\title{
Resistance of Haemonchus contortus to monepantel in sheep: first report in Espírito Santo, Brazil
}

\author{
Resistência de Haemonchus contortus ao monepantel em ovinos: primeiro \\ relato no Espírito Santo - Brasil
}
Marcus Vinicius Gonçalves Viana ${ }^{1}$; Ygor Henrique da Silva² (D); Isabella Vilhena Freire Martins ${ }^{\text {* }}$ (D); Fabio Barbour $\mathrm{Scott}^{2}$ (D)

\author{
${ }^{1}$ Departamento de Medicina Veterinária, Universidade Federal do Espírito Santo - UFES, Alegre, ES, Brasil \\ ${ }^{2}$ Departamento de Parasitologia Animal, Instituto de Veterinária, Universidade Federal Rural do Rio de Janeiro - UFRRJ, \\ Seropédica, RJ, Brasil
}

How to cite: Viana MVG, Silva YH, Martins IVF, Scott FB. Resistance of Haemonchus contortus to monepantel in sheep: first report in Espírito Santo, Brazil. Braz J Vet Parasitol 2021; 30(4): e013121. https://doi.org/10.1590/S1984-29612021089

\begin{abstract}
The objective of this study was to provide the first report of resistance of Haemonchus contortus to monepantel in sheep in Espírito Santo. The study was conducted in a property with history of monepantel use since 2014 and register of low efficacy in studies conducted over the past few years with fecal egg count reduction test. Lambs born on the property (males and females aged approximately 100 days) were selected and after eggs per gram of feces (EPG) analysis on fecal samples, these were divided into two groups: a group treated with monepantel $(2.5 \mathrm{mg} / \mathrm{Kg}$ ) and a control group without anthelmintic treatment. Seven days later, the animals were euthanized to recover parasites from the gastrointestinal tract. The efficacy of the treatment was $61.35 \%$ against $H$. contortus, thus proving that anthelmintic resistance to monepantel was present.
\end{abstract}

Keywords: Anthelmintic resistance, control, nematode, ruminants.

\section{Resumo}

O objetivo deste estudo foi fornecer o primeiro relato de resistência de Haemonchus contortus ao monepantel em ovinos no Espírito Santo. O estudo foi conduzido em uma propriedade com histórico de uso de monepantel, desde 2014, e registro de baixa eficácia em estudos conduzidos nos últimos anos, utilizando-se testes de redução de contagem de ovos por grama de fezes (OPG). Cordeiros nascidos na propriedade (machos e fêmeas com idade aproximada de 100 dias) foram selecionados e, após contagem de OPG, foram divididos em dois grupos: um grupo tratado com monepantel $(2,5 \mathrm{mg} / \mathrm{kg}$ ) e um grupo controle, sem tratamento com anti-helmíntico. Após 7 dias, os animais foram eutanasiados para a recuperação dos parasitos no trato gastrointestinal. $\mathrm{O}$ tratamento apresentou eficácia de $61,35 \%$ para $H$. contortus, comprovando que a resistência anti-helmíntica ao monepantel foi presente.

Palavras-chave: Anti-helmíntico, controle, nematoide, ruminantes. 
Gastrointestinal helminthic infections are the main cause of economic losses in sheep farming systems, in addition to decreasing animal welfare. The genus Haemonchus is among the main gastrointestinal helminth found in some regions of Brazil and especially in sheep. The species Haemonchus contortus causes enormous damage to sheep industry, being considered a limiting factor for this economic activity (Albuquerque et al., 2017; Claerebout et al., 2020; Starling et al., 2017).

Indiscriminate use of anthelmintic drugs to control helminthic infections without selection criteria commonly generates resistance of these parasites to the drugs used. This problem has been proven in several regions of Brazil in relation to Haemonchus spp. In the southeastern region of Brazil, Almeida et al. (2010) found Haemonchus resistant to albendazole, closantel, levamisole, moxidectin, organophosphate and ivermectin. Other reports of resistance to ivermectin, albendazole, levamisole and moxidectin has been published (Veríssimo et al., 2012; Nunes et al., 2013).

Monepantel, an aminoacetonitrile derivative, is a drug that was developed with the objective of controlling nematodes in ruminants. However, there are already records of populations of gastrointestinal nematodes that are resistant to monepantel, in several countries. In New Zealand, Scott et al. (2013) reported the presence of resistance of Trichostrongylus colubriformis to monepantel. In Uruguay, Mederos et al. (2014) confirmed the presence of resistance of $\mathrm{H}$. contortus to this drug. In Brazil, there have been some reports of monepantel-resistant populations of Haemonchus spp. (Albuquerque et al., 2017; Mallmann et al., 2018; Martins et al., 2017) and also Trichostrongylus colubriformis (Cintra et al., 2016).

The objective of the present study was to confirm the presence of a $\mathrm{H}$. contortus population resistant to monepantel in a sheep farm in Espírito Santo.

This study was conducted in accordance with the ethical principles for animal experimentation and was approved by the Ethics Committee for Animal Use (CEUA) of the Federal University of Espírito Santo, protocol number 018/2018.

The experiment was carried out on a farm located in the rural area of the municipality of Alegre, state of Espírito

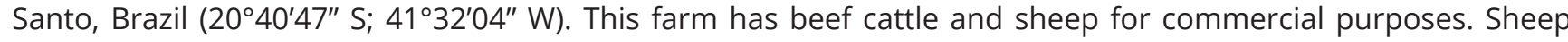
management is carried out in a module rotating 12 paddocks of Brachiaria sp, which comprises approximately 4.8 hectares.

The farm herd was monitored by fecal egg count reduction test (FECRT), through eggs per gram of feces (EPG) and fecal cultures, throughout 2015, 2017 and 2019, to identify the predominant nematode groups and determine the effectiveness of the anthelmintics used, as described by Coles et al. (1992).

The history control of helminths on the property consisted in the use of anthelmintics based on albendazole, ivermectin, levamisole and monepantel. The selection criteria for treatment were based on the animals EPG counting or $\mathrm{FAMACHA}^{\circledR}$ method. However, in general, these drugs were used indiscriminately in animals on a monthly or bimonthly frequency, alternating the basis used according to the availability of different drugs at the time of application.

For the study, 20 lambs born on the property were subjected to two fecal collections, on days -10 and -2 before treatment, to ascertain the counts of EPG by means of the McMaster technique (Gordon \& Whitlock, 1939). The fecal samples of the animals were collected and send to the Parasitology Laboratory of the Veterinary Hospital of the Agricultural Sciences Center, Federal University of Espírito Santo (HOVET-CCAE-UFES), where they were immediately processed.

On the day following EPG verification on day -10, stool cultures were performed according to the methodology described by Roberts \& O'Sullivan (1950). Later, third-stage larvae were recovered and identified as described by Ueno \& Gonçalves (1998).

From among these 20 selected lambs, after analyzing the results from the tests on days -10 and $-2,14$ lambs (five males and nine females) from industrial crosses (White Dorper x Santa Inês), with an average age of 100 days, average initial weight of $17.5 \mathrm{~kg}$ and EPG > 1000, were selected (Table 1). This selection was made in accordance with the recommendations of the World Association for the Advancement of Veterinary Parasitology (WAAVP) (Coles et al., 2006). These lambs were divided into two groups containing seven animals each: the first group received treatment and the second was the non-treated control group.

The animals were weighed on a mechanical scale in order to calculate the volume of the anthelmintic to be administered to each lamb. The drug used in the treatment was monepantel (Zolvix ${ }^{\circledR}$, Novartis) at a dose of $2.5 \mathrm{mg}$ / Kg orally, which was administered in accordance with the manufacturer's recommendations on day 0.

After seven days of deworming, the animals were euthanized with the use of previous anesthesia with xylazine and general anesthesia with sodium thiopental followed by potassium chloride. The necropsy was performed by 
Table 1. Randomized distribution of sheep naturally infected by gastrointestinal nematodes, with formation of a treatment group and a control group based on individual mean values of eggs per gram of feces (EPG) in examinations performed on of days -10 and -2 .

\begin{tabular}{ccccc}
\hline Group & Animal & Weight (Kg) & EPG & $\begin{array}{c}\text { Standard } \\
\text { deviation }\end{array}$ \\
\hline TREATED & 527 & 13.5 & 5733 & 2548.6 \\
& 151 & 13.0 & 3949 & \\
& 565 & 20.0 & 3388 & \\
& 87 & 17.5 & 2466 & \\
CONTROL & 18.0 & 1877 & \\
& 229 & 19.5 & 1488 & \\
& 93 & 16.0 & 1322 & \\
& 122 & 18.0 & 4433 & \\
& 250 & 13.0 & 3699 & \\
& 630 & 14.5 & 2799 & \\
\end{tabular}

${ }^{1}$ geometric mean.

separating the omentum from the pre-stomachs, abomasum and mesentery, the pre-stomachs and abomasum being opened by the greater curvature and the intestines at the insertion of the mesentery, collecting the gastric and intestinal contents, in addition to examining the mucous membranes.

In accordance with WAAVP recommendations (Wood et al., 1995), the contents of the abomasum, small intestine and large intestine were collected and fixed in 10\% formalin to preserve the specimens. All parasites in the 10\% subaliquot of this total were counted and identified according to their morphological characteristics (Ueno \& Gonçalves, 1998).

The data were evaluated to obtain the mean and standard deviation of the helminths recovered in the treated and control groups, using the R software (R Core Team, 2020), and the geometric mean was applied, as recommended by the World Association for the Advancement of Veterinary Parasitology (WAAVP) (Coles et al., 1992) and the United Nations Food and Agriculture Organization (FAO, 2004). Efficacy was calculated via the following formula: \% efficacy $=$ (mean number of helminths in control animals - mean number of helminths in treated animals) $/$ (mean number of helminths in control animals) $\times 100$.

Parasite counts were subjected to the Levene test to assess whether the data were homogeneous or not; and to the Shapiro-Wilk test to assess whether the data had normal distribution or not. Dunn's test was used to verify significant difference $(p \leq 0.05)$ of the mean numbers of helminths recovered, using the R software (R Core Team, 2020).

The fecal count reduction tests performed on the property in 2015, 2017 and 2019 revealed different efficacy levels of monepantel in naturally infected sheep. Starling et al. (2017) found 92.2\% of efficacy 14 days after treatment. In 2017, FECRT monitoring on 24 naturally infected sheep treated only with monepantel, showed that it had an efficacy rate of $64.3 \%$ (unpublished data). In addition, in 2019, on the same farm, FECRT monitoring on 21 sheep showed that the efficacy of monepantel was close to 1\%, 14 days after treatment (unpublished data).

The larvae that emerged from the fecal cultures showed morphological characteristics typical of Trichostrongylidae larvae, with $87 \%$ of Haemonchus spp. and $13 \%$ of Oesophagostomum spp. larvae.

In the abomasum, $H$. contortus was found in both groups, with an average of $379( \pm 191)$ specimens in the treated group and $980( \pm 1412)$ in the control group, without significant difference between group means $(p=0.896)$. For $H$. contortus, the drug efficacy was $61.35 \%$.

In the small intestine, the cestode Moniezia spp. was found in both study groups, and in the large intestine, the helminths Oesophagostomum columbianum and Trichuris spp. were found. O. columbianum presented in average 10 ( \pm 17) and 47.1 ( \pm 79 ) parasites in the treated and control groups, respectively, showing an efficacy of $78.8 \%$. The low levels of efficacy may be attributed to the lack of indication of the product for the control of Oesophagostomum. 
Increasingly, studies evaluating the effectiveness of antiparasitic drugs have shown reductions in the effectiveness of the main drugs available, such as monepantel (Zolvix ${ }^{\circ}$, Novartis), which is the drug with anthelmintic activity that has more recently come onto the market (Bartley et al., 2019; Ploeger \& Everts, 2018). The greatest concern regarding the reduction in the effectiveness of these drugs is in relation to $\mathrm{H}$. contortus, the main nematode species in sheep farming (Albuquerque et al., 2017; Claerebout et al., 2020; Starling et al., 2017).

In order to understand the mechanisms that lead to the condition of parasite resistance, many studies have been developed with the aim of defining the main risk factors for this condition. It has been noted that indiscriminate treatment together with frequent use of different active ingredients leads to onset of the resistance within a short period of time (Lamb et al., 2017; Rose et al., 2015).

According to the historical survey on the farm of this study, the animals had received approximately 15 treatments with monepantel (Zolvix®, Novartis), as management against helminths, over the 18 months preceding this study. Frequent suppressive treatment with anthelmintics such as monepantel quickly leads to parasite resistance, due to rapid selection of resistant populations (Albuquerque et al., 2017; Lamb et al., 2017; Rose et al., 2015).

The history of anthelmintics used on this farm and the poor effectiveness of the deworming management implemented demonstrate that excessive use of anthelmintics, together with the lack of specific criteria for treatment and absence of any strategic control program have led to a progressive selection, from 2015 to 2019, of a monepantel-resistant $H$. contortus population. Mallmann et al. (2018) highlighted the same postulates as determining factors for selection of resistant populations of $H$. contortus.

This result demonstrates that gastrointestinal nematodes should not be controlled solely through the use of anthelmintics. A set of preventive measures should be used, while always seeking to reduce the predisposing factors for the emergence of parasitic resistance. A large number of studies addressing this topic have now presented this viewpoint (Besier, 2012; Cintra et al., 2016; Starling et al., 2017).

Another important factor to be taken into account is the periodic evaluation of the herd's by fecal examination in order to determine the degree of infection. From these values, selection criteria for the treatment of animals at the "trigger level" can be created, as described by Besier (2012). Thus, the number of treatments performed and the rotation of anthelmintics on the properties reduced, delaying the establishment of resistant populations.

The presented results demonstrate the presence of a monepantel resistant population of $H$. contortus in sheep from Espírito Santo, Brazil

\section{Acknowledgements}

This study was financed in part by the Coordination Office for Improvement of Higher-Education Personnel (Coordenação de Aperfeiçoamento de Pessoal de Nível Superior, Brazil (CAPES)) under its finance code 001.

\section{References}

Albuquerque ACA, Bassetto CC, de Almeida FA, Amarante AFT. Development of Haemonchus contortus resistance in sheep under suppressive or targeted selective treatment with monepantel. Vet Parasitol 2017; 246: 112-117. http://dx.doi.org/10.1016/j. vetpar.2017.09.010. PMid:28969773.

Almeida FA, Garcia KCOD, Torgerson PR, Amarante AFT. Multiple resistance to anthelmintics by Haemonchus contortus and Trichostrongylus colubriformis in sheep in Brazil. Parasitol Int 2010; 59(4): 622-625. http://dx.doi.org/10.1016/j.parint.2010.09.006. PMid:20887800.

Bartley DJ, Hamer K, Andrews L, Sargison ND, Morrison AA. Multigeneric resistance to monepantel on a UK sheep farm. Vet Parasitol 2019; 276S: 100003. http://dx.doi.org/10.1016/j.vpoa.2019.100003. PMid:34311939.

Besier RB. Refugia-based strategies for sustainable worm control: factors affecting the acceptability to sheep and goat owners. Vet Parasitol 2012; 186(1-2): 2-9. http://dx.doi.org/10.1016/j.vetpar.2011.11.057. PMid:22197747.

Cintra MCR, Teixeira VN, Nascimento LV, Sotomaior CS. Lack of efficacy of monepantel against Trichostrongylus colubriformis in sheep in Brazil. Vet Parasitol 2016; 216: 4-6. http://dx.doi.org/10.1016/j.vetpar.2015.11.013. PMid:26801587.

Claerebout E, De Wilde N, Van Mael E, Casaert S, Velde FV, Roeber F, et al. Anthelmintic resistance and common worm control practices in sheep farms in Flanders, Belgium. Vet Parasitol Reg/ Stud Rep 2020; 20: 100393. https://doi.org/10.1016/j. vprsr.2020.100393. 
Coles GC, Bauer C, Borgsteede FHM, Geerts S, Klei TR, Taylor MA, et al. World Association for the Advancement of Veterinary Parasitology (W.A.A.V.P.) methods for the detection of anthelmintic resistance in nematodes of veterinary importance. Vet Parasitol 1992; 44(1-2): 35-44. http://dx.doi.org/10.1016/0304-4017(92)90141-U. PMid:1441190.

Coles GC, Jackson F, Pomroy WE, Prichard RK, von Samson-Himmelstjerna G, Silvestre A, et al. The detection of anthelmintic resistance in nematodes of veterinary importance. Vet Parasitol 2006; 136(3-4): 167-185. http://dx.doi.org/10.1016/j. vetpar.2005.11.019. PMid:16427201.

Food and Agriculture Organization - FAO. Resistance management and integrated parasite control in ruminants - guidelines FAO [online]. Rome: FAO; 2004 [cited 2021 mar 20]. Available from: http://www.fao.org/3/ag014e/ag014e.pdf

Gordon HM, Whitlock HV. A new technique for counting nematode eggs in sheep faeces. J Sci Ind Res 1939; 12 (1): $50-52$.

Lamb J, Elliott T, Chambers M, Chick B. Broad spectrum anthelmintic resistance of Haemonchus contortus in Northern NSW of Australia. Vet Parasitol 2017; 241: 48-51. http://dx.doi.org/10.1016/j.vetpar.2017.05.008. PMid:28579030.

Mallmann PM Jr, Raimondo RFS, Rivero BRC, Jacondino LR, Gonçalves AS, Silveira BO, et al. Resistance to monepantel in multiresistant gastrointestinal nematodes in sheep flocks in Rio Grande do Sul. Semina: Ciênc Agrár 2018; 39(5): 2059-2070. http://dx.doi.org/10.5433/1679-0359.2018v39n5p2059.

Martins AC, Bergamasco PLF, Felippelli G, Tebaldi JH, Moraes MFD, Testi AJP, et al. Haemonchus contortus resistance to monepantel in sheep: fecal egg count reduction tests and randomized controlled trials. Semina: Ciênc Agrár 2017; 38(1): 231-238. http://dx.doi. org/10.5433/1679-0359.2017v38n1p231.

Mederos AE, Ramos Z, Banchero GE. First report of monepantel Haemonchus contortus resistance on sheep farms in Uruguay. Parasit Vectors 2014; 7: 598. http://dx.doi.org/10.1186/s13071-014-0598-z. PMid:25515711.

Nunes RLS, Dos Santos LL, Bastianetto E, De Oliveira DAA, Brasil BSFA. Frequency of benzimidazole resistance in Haemonchus contortus populations isolated from buffalo, goat and sheep herds. Braz J Vet Parasito/ 2013; 22(4): 548-553. https://doi.org/10.1590/ S1984-29612013000400015.

Ploeger HW, Everts RR. Alarming levels of anthelmintic resistance against gastrointestinal nematodes in sheep in the Netherlands. Vet Parasitol 2018; 262: 11-15. http://dx.doi.org/10.1016/j.vetpar.2018.09.007. PMid:30389005.

R Core Team. R: A language and environment for statistical computing. Vienna, Áustria: R Foundation for Statistical Computing, 2020.

Roberts FHS, O'Sullivan PJ. Methods for egg counts and larval cultures for strongyles infesting the gastro-intestinal tract of cattle. Aust J Agric Res 1950; 1(1): 99-102. http://dx.doi.org/10.1071/AR9500099.

Rose H, Rinaldi L, Bosco A, Mavrot F, De Waal T, Skuce P, et al. Widespread anthelmintic resistance in European farmed ruminants: a systematic review. Vet Rec 2015; 176(21): 546. http://dx.doi.org/10.1136/vr.102982. PMid:25762583.

Scott I, Pomroy WE, Kenyon PR, Smith G, Adlington B, Moss A. Lack of efficacy of monepantel against Teladorsagia circumcincta and Trichostrongylus colubriformis. Vet Parasito/ 2013; 198(1-2): 166-171. http://dx.doi.org/10.1016/j.vetpar.2013.07.037. PMid:23953148.

Starling RZC, Martins IVF, Alves CS, Viana MVG, Dietrich WS. Diagnóstico in vivo da sensibilidade de nematoides a diferentes antihelmínticos em ovinos criados em sistema semi-intensivo. Arch Vet Sci 2017; 22(2): 38-47. http://dx.doi.org/10.5380/avs. v22i2.42277.

Ueno H, Gonçalves PC. Manual para diagnóstico das helmintoses de ruminantes. 4. ed. Tokyo: JICA; 1998.

Veríssimo CJ, Niciura SCM, Alberti ALL, Rodrigues CFC, Barbosa CMP, Chiebao DP, et al. Multidrug and multispecies resistance in sheep flocks from Sao Paulo state, Brazil. Vet Parasitol 2012; 187(1-2): 209-216. http://dx.doi.org/10.1016/j.vetpar.2012.01.013. PMid:22341829.

Wood IB, Amaral NK, Bairden K, Duncan JL, Kassai T, Malone JB Jr, et al. World Association for the Advancement of Veterinary Parasitology (W.A.A.V.P.) second edition of guidelines for evaluating the efficacy of anthelmintics in ruminants (bovine, ovine, caprine). Vet Parasito/ 1995; 58(3): 181-213. http://dx.doi.org/10.1016/0304-4017(95)00806-2. 